Cambridge Law Journal, 80(2), July 2021, pp. 366-396 C Cambridge Law Journal and Contributors 2021. This is an Open Access article, distributed under the terms of the Creative Commons Attribution licence (http://creativecommons.org/licenses/ by $/ 4.0 /$ ), which permits unrestricted re-use, distribution, and reproduction in any medium, provided the original work is properly cited.

doi: $10.1017 / \mathrm{S} 0008197321000295$

\title{
ANALOGY REVERSED
}

\author{
SHIVPRASAD SWAMINATHAN*
}

ABSTRACT. Standard accounts of analogy in law picture it as reasoning from the past case (source) to a solution in the case at hand (target). This article argues that the normatively constraining invocations of similarity or likeness presupposed by standard accounts do not obtain. It then sketches an alternative account based on Michael Polanyi's idea of polycentricity (not Lon Fuller's) on which the orientation of analogical reasoning is reversed. A past case (here "target") is picked and framed in certain ways to persuade the interlocutor about the decision independently reached in the present case (here "source") through the guidance of tacit knowledge (involving anticipation of what is likely to pass muster with the legal community) which normatively constrains the process.

KEYWORDS: analogical reasoning, polycentricity, Michael Polanyi, tacit knowledge, persuasion, rhetoric.

\section{Questioning the Standard Picture}

Analogical reasoning is arguably the chief "organon" of the common law mind ${ }^{1}$ one which happens to trace its provenance to Aristotle's Organon, no less. ${ }^{2}$ It involves reasoning with cases on the basis of their likeness or similarity. ${ }^{3}$ In so far as it involves reasoning with cases, there is a contiguity between reasoning with precedent or authority and reasoning with analogy. ${ }^{4}$ If a past case is invoked as a precedent or direct authority, one seeks to subsume the case at hand under the past one. If there is "no authority" as Martin B. put it, the case is decided upon "legal analogy". 5 When a past case is invoked as analogue, one seeks to "extend" it to the

* Professor, Jindal Global Law School, O.P. Jindal Global University, Delhi (NCR). Address for Correspondence: Sonipat Narela Road, Sonipat, Haryana 131001, India. Email: sswaminathan@jgu. edu.in. Many thanks are due to Hanoch Dagan, Andrew Halpin, Martin Mork, V. Niranjan, Giovanni Battista Ratti, Ira Chaddha Sridhar and Zhong Xing Tan who commented on earlier versions of this paper.

1 B.N. Cardozo, Nature of the Judicial Process (New Haven 1921), 38.

2 Aristotle's Rhetoric, Topics and Prior Analytics are the fons et origo of the method.

3 J. Austin, Lectures on Jurisprudence, 4th ed., by R. Campbell (ed.) (London 1873), 1040. There are accounts of analogical reasoning in a number of spheres of thought. However, throughout this article, "analogical reasoning" shall refer to the process familiar to common lawyers, eo nomine.

4 M.A. Eisenberg, The Nature of the Common Law (Cambridge, MA 1991), 83.

5 Fletcher v Rylands (1865) 159 E.R. 737, (1865) 3 Hurl. \& C. 774, 793. 
case at hand. ${ }^{6}$ To all appearances, there is quite an assortment of views to be had on analogical reasoning in the common law. However, practically, the whole lot of them - including the critics of analogical reasoning share in common the presupposition that the point of analogical reasoning is to reason from the past case (source) to a solution in the case at hand (target). ${ }^{7}$ The "extension" is thought to employ the following structure. Since the source and target have characteristic $x$ in common, and source has characteristic $y$, the target too is thought to share characteristic $y .{ }^{8}$ In other words, standard accounts of the process portray it as reasoning from known similarities to argue that the cases should be treated similarly in other respects as well. This constitutes the fulcrum of agreement between those who intramurally disagree with one another about how one might reason from the source to the target. Broadly, three views are taken on how one might go about traversing this: (1) through the mediation of a rule or principle grounding the similarity or likeness; ${ }^{9}(2)$ through an intuitive grasp of similarity; ${ }^{10}$ and (3) through the mediation of a theory connecting past cases to the case at hand. ${ }^{11}$ These approaches are collectively referred to as standard accounts of analogical reasoning.

On the model of normativity underlying standard accounts of analogical reasoning, the past case (source) yields an answer to the case at hand (target), which it is the function of decision-making to be responsive to. The phrases "yields an answer to" and "being responsive to" are used capaciously so as to encompass the entire epistemological spectrum spanned by standard accounts of analogical reasoning: rule-based, intuition-based and theory-based. The point here is that, on the model of normativity

${ }^{6}$ The term "extend" is commonly used to describe the process of analogical reasoning; Austin, Lectures on Jurisprudence, 1039; N. MacCormick, Legal Reasoning and Legal Theory (Oxford 1978), 188; J. Raz, Authority of Law (Oxford 1979), 207; G. Postema, "A Similibus ad Similia: Analogical Thinking in Law" in Douglas Edlin (ed.), Common Law Theory (Cambridge 2007), 102.

7 Postema, "A Similibus ad Similia", 104.

8 C. Sunstein, "On Analogical Reasoning" (1993) 106 Harvard Law Review 106.

9 Eisenberg, The Nature of the Common Law, 86-87. S. Brewer, "Exemplary Reasoning: Semantics, Pragmatics, and the Rational Force of Legal Argument by Analogy" (1996) 109 Harvard Law Review 974; P. Westen, "On Confusing Ideas: A Reply" (1982) 91 Yale Law Journal 1153; C. Sunstein, Legal Reasoning and Political Conflict (Oxford 1996), 62-100.

${ }^{10}$ L. Weinreb, Legal Reason: The Use of Analogy in Legal Argument (Cambridge 2005); B. Leiter, "Heidegger and the Theory of Adjudication" (1997) 106 Yale Law Journal 253; and arguably E. Levi, An Introduction to Legal Reasoning (Chicago 1949). Although Levi does not specify how judgments of similarity are made, scholars argue that he relies on intuitionism: Eisenberg, The Nature of the Common Law, 86; M.S. Moore, "Precedent, Induction and Ethical Generalization" in L. Goldstein (ed.), Precedent in Law (Oxford 1987), 192.

${ }^{11}$ Unlike the rule-based model where the movement is from one case to another, here one moves from a cluster of cases to the case at hand with the mediation of a coherentist theory. Accounts of this kind include Ronald Dworkin's and G. Postema's: R. Dworkin, Taking Rights Seriously (Cambridge, MA 1978). Although here Dworkin himself does not describe his approach as "analogical reasoning", Raz describes it as an "extreme case of total faith in analogical arguments": Raz, Authority of Law, 205-06. Later, Dworkin expressly asserts that "theory" of the sort he endorses does the work in analogical reasoning: R. Dworkin, "In Praise of Theory" (1997) 29 Arizona St. L.J. 353. Another example of this is Postema's account: Postema, "A Similibus ad Similia", 123 ("the rational pressure which gives shape to the emerging sense of likeness comes from all members of the ... comparison class"); later he argues for "systemic coherence" by invoking Dworkin at 131 . 
presupposed by these accounts, there is such a thing as a normatively correct and inescapable invocation of similarity or likeness inherent in the "source" analogue. This is something the decision maker in the present case is pictured on the model as being responsive to.

This paper argues that there is a double dissonance between the phenomenology of analogical reasoning and its depiction by standard theoretical accounts. For one, it will be argued - with illustrations prayed in aid that it is far from a correct depiction of analogical reasoning; and that the decision maker has leeway in selecting and framing the "source" analogue in ways which undermine the plausibility of the standard picture. For another, it will be argued - with the support of an argument going back to David Hume - that the direction of fit between the past case (the so-called "source") and the case at hand (so-called "target") in analogical reasoning is the reverse of what the standard picture assumes. In other words, the decision to reach a particular result in the present case is prior to and has a bearing upon the selection and framing of the so-called "source" analogue. The sequitur to this Humean move is the familiar argument that analogical reasoning is a form of rhetorical reasoning - where a past case is picked for its value as a rhetorical counter to persuade the interlocutor about the acceptability of a prior, independent decision on the substance of the case. In the literature, this "rhetorical" argument typically comes intertwined with the view that the normative constraints supposed by the standard theoretical accounts of analogical reasoning do not obtain. And without these normative constraints in place, the argument goes, analogical reasoning becomes "anything goes" rhetorical reasoning, which is to say, a pejorative or nihilistic version of the notion of rhetoric. Indeed, that is the damning verdict some influential critics of analogical reasoning such as Richard Posner have reached. ${ }^{12}$

However, rather than embracing that sceptical, debunking denouement, this paper seeks to conserve the phenomenon so integral to common law reasoning by sketching instead, a rival account of analogical reasoning based on an alternative model of normativity - by building on Michael Polanyi's idea of "polycentricity". And to be sure, this alternative account makes allowance for the reverse direction of fit of analogical reasoning adverted to by Hume, as it also does for the point that analogical reasoning is ostensibly rhetorical in nature. A polycentric system of decision-making, such as the common law, involves a number of decision-makers who go about making their decisions by anticipating - with the guidance of tacit knowledge - what is likely to pass muster with the community of decisionmakers. And having thus arrived at a decision, seek to persuade the community by justifying the decision at hand by showing its similarity with

12 R. Posner, "Reasoning by Analogy" (2006) 76 Cornell Law Review 761. 
previously decided cases. Polycentric decision-making can thus be understood as a two-pronged process. The first prong is epistemological, involving as it does, "discovery" in the form of anticipating what is likely to pass muster with the group, while the second prong is rhetorical, involving "justification" of the decision by the invocation of the past case, similar to the decision being handed down, as example or analogue.

This alternative account acknowledges the reversal in the direction of fit - pointed out by Hume - between what we are schooled to treat as the "source" and "target" analogues. On this account, the direction of fit of analogical reasoning shall be found to be from the present case (the so-called "target") to the past case (the so-called "source"). And the alternative account also acknowledges - the point pressed by sceptics of analogical reasoning - that the function of analogical reasoning is to persuade. On this picture, past cases (here reversed to "targets") are picked and framed in certain ways for their value as rhetorical counters to justify the decision independently reached in the case at hand (here reversed to "source").

Despite its reversing the direction of legal reasoning and the centrality of rhetoric on this account, it will be argued that the account yields a sound model of normativity - one on which there are normative constraints put in place by the epistemological prong of the account which is to say, by judgments anticipating (with the guidance of tacit knowledge) what is likely to be acceptable to the community of decision-makers. The crucial part of this alternative picture will be the elucidation of a different model of normativity yielded by the polycentric account (motivational model of normativity), and its contrast with the model of normativity presupposed by standard accounts (truth-based model of normativity).

It might be helpful briefly to adumbrate here the layout of the argument advanced in the rest of the paper. Section II outlines objections to the standard picture of analogical reasoning and argues that the normative constraints supposed by it do not exist. In Section III, we turn to the polycentric account of analogical reasoning; its two prongs, epistemological and rhetorical; and the model of normativity on which it is based - termed here as the motivational model of normativity. Here we will also examine the difference between the two models of normativity: truth-based and motivational. Finally, Section IV will argue that the alternative polycentric account sketched here makes better sense of two features thought to be closely associated with analogical reasoning than do standard accounts, namely: the principle of "treating like cases alike" and common law incrementalism.

\section{Objections to the Standard Picture}

Primarily, three objections will be marshalled against the standard picture of analogical reasoning. (1) Since the framing of the source analogue is a malleable process, judgments of similarity in analogical reasoning cannot 
be normatively constraining - leeway is available and choice is inevitable in how the so-called "source" analogue is framed. (2) The standard picture gets the direction of fit of analogical reasoning scrambled - the decision to invoke the so-called "source" analogue is not motivated by any normative constraints put in place by the source analogue itself; but rather it is the prior, independent decision to reach a certain result which, in the first place, motivates the choice to frame the source analogue in a certain way. (3) Analogical reasoning is rhetorical reasoning - where a past decision is picked for its value as a rhetorical counter to persuade the interlocutor about the result in the decision. In what follows, arguments (2) and (3) are treated conjointly since the latter is a sequitur of and follows from the former. The common thread running through these objections is that the orientation of analogical reasoning runs from present case-to-past case, rather than running from past case-to-present case, as we are traditionally schooled to understand.

\section{A. Malleability of Analogy and Accounting for the Element of Choice}

Standard accounts of analogical reasoning seem to enter the scene analytically a step too late, as it were. They pay little attention to how the so-called "source" analogue is framed by a court. Judgments of similarity are crucially dependent on how one cognises the case that another is being judged similar in comparison to. To see $\mathrm{B}$ as similar to $\mathrm{A}$, one has first to cognise A in a certain way. That acts as the "fixed point" from which one - going by standard accounts - launches analogical reasoning. ${ }^{13}$ Framing involves cognising a source analogue as falling within a certain "category or set of categories". ${ }^{14}$ The category the source is put into, in turn, is closely tied with whether or not the case gets cognised as an instantiation of some rationale (which is typically wide). ${ }^{15}$ Once the source analogue is framed as falling under a category, it paves the path for the extension of the rationale to the case at hand, as the examples discussed later in this section shall reveal. This is so because the structure of argument by analogy, in Razian terms, comes to this - if the rationale applies to the source analogue, it ought to apply to the target. ${ }^{16}$ This makes the initial framing of the analogy crucial.

Standard accounts of analogical reasoning presuppose that framing of the source analogue is an objective exercise which does not admit of an element of choice. As Austin puts it, "it is known (or assumed) before the reasoning that a given something is true" of the source analogue. ${ }^{17}$ Without

\footnotetext{
13 M. Koszowski, Analogical Reasoning in Law (Newcastle 2019), 147.

14 MacCormick, Legal Reasoning and Legal Theory, 186.

15 Ibid., at 186.

16 Raz, Authority of Law, 204.

17 Austin, Lectures on Jurisprudence, 1040 (emphasis added).
} 
this base or fixed point, standard accounts of analogical reasoning can never really get off the ground. ${ }^{18}$ If the issue of how to frame the source is open for choice on each occasion - not being objectively identifiable at the outset - there is no meaningful way in which one could ever really reason from a source to a target analogue, for it would require the inexplicable prior step of choosing how to frame the source analogue. But to concede that framing of a source analogue is a malleable process involving an element of choice would be to throw a spanner in the workings of the normative model underlying the standard picture.

The gravamen of the charge then comes to this. Since the framing of analogy is a malleable process, involving as it does an element of choice, judgments of similarity in analogical reasoning cannot possibly be normatively constraining. Joseph Raz, ${ }^{19}$ Neil MacCormick ${ }^{20}$ and Richard Posner ${ }^{21}$ have each argued that analogical reasoning is not normatively constraining, albeit reaching that conclusion through other routes. The route taken here involves arguing that the problem of malleability of analogical reasoning is of a piece with the better appreciated phenomenon of malleability in the context of reasoning with precedent. In both cases, it turns out, the malleability is attributable to the fact that the legal past is not static. It might be in order quickly to rehearse the contours of the problem in the context of reasoning with precedent before seeing how its parallel applies to reasoning by analogy.

It is now trite learning that precedents in the common law do not come with "rules" embedded in them, and that the future court seized of a lis plays an active role in determining what the rule in a past case is. ${ }^{22}$ This is, of course, the most conspicuous reason why searches for an algorithm or test for detecting the ratio of a case have come a cropper. ${ }^{23}$ But there is another, less obvious factor which equally contributes to the dynamism of the process - a common law decision is capable of being stated and restated in multiple ways. There are two reasons for this. One, is the level of generality in which the holding in a past case can be cast. To use Julius Stone's example - which has since become ubiquitous in discussions on precedent - the holding in Donoghue $v$ Stevenson is consistent with multiple "rules" ranging from the narrow (snails in bottles) to the

${ }^{18}$ Steven Burton describes it as the "base point" from which to do analogical reasoning: S. Burton, Introduction to Law and Legal Reasoning (Boston and Toronto 1985), 26.

19 Raz, Authority of Law, 206 (judges not "legally obligated to use analogical arguments") (emphasis in original).

${ }^{20}$ MacCormick says arguments by analogy only show that some conclusions are "permissible", not that they are "obligatory": MacCormick, Legal Reasoning and Legal Theory, 182, 188-89.

${ }^{21}$ Posner argues past analogues are "information" not "authority": R. Posner, The Problems of Jurisprudence (Cambridge, MA 1991), 93.

22 S. Swaminathan, "Mos Geometricus and the Common Law Mind: Interrogating Contract Theory" (2019) 82 M.L.R. 46, 58-65.

23 Raz, Authority of Law, 183-84. 
wide (general duty of care). ${ }^{24}$ The other, is multiple opinions expressed by judges and the opportunity presented to a future court of latching on to any of the opinions and finding the ratio there. ${ }^{25}$ A telling example of this is the entirely novel ratio recently found by the Supreme Court in the century-old decision of Dunlop $v$ New Garage Motors, ${ }^{26}$ by the simple expedient of turning to the opinion of another judge in the case. ${ }^{27}$ Thanks to these features, as Brian Simpson put it, the rules of the common law cannot be engraved on to tablets or counted - as if they were sheep. ${ }^{28}$ In fact, Levi himself - one of the most influential supporters of the standard picture of analogical reasoning - is acutely aware of this phenomenon in case of reasoning with precedent, which prompts him to describe the common law as a "moving" system of classification. ${ }^{29}$ As Grant Lamond points out, without appreciating this malleability of precedent in the common law, one cannot really account for the process of distinguishing. ${ }^{30}$ In a similar vein, it is argued here, the malleability of the common law has implications for analogical reasoning as well. Considerations similar to those found when reasoning with precedent apply mutatis mutandis to analogical reasoning.

It will be argued with illustrations prayed in aid that there is no normatively constraining pathway of extending a past case (the so-called "source") analogically. And that a prior, independent choice is necessarily involved in what one picks as an analogy and how one frames it. To see this in action, let us consider the movement of the law of frustration, from the celebrated case of Taylor $v$ Caldwell $^{31}$ to the early twentieth-century coronation cases. Prior to Taylor v Caldwell, the common law rule - going back all the way to Paradine $v$ Jane (1647) - was that change in circumstances would not discharge contractual obligations. The only exception to the rule was death or perhaps disability in case of contracts of a personal nature. ${ }^{32}$ Taylor $v$ Caldwell was to alter the status quo. The case concerned a contract to hire a hall and gardens adjoining it for a music concert. Before the concert, the hall was destroyed by fire. Blackburn J., relying on Pothier and the Digest (i.e. Roman law) held that "the Music Hall having ceased to exist, without fault of either party, both parties are excused". ${ }^{33}$ Taylor had nothing to say on the "teleological notion" of what happens when the object or

\footnotetext{
24 J. Stone, The Province and Function of Law (Cambridge, MA 1950), 187-88.

25 Swaminathan, "Mos Geometricus and the Common Law Mind", 63-65.

26 Dunlop Pneumatic Tyre Co. Ltd. v New Garage \& Motor Co. Ltd. [1915] A.C. 79.

27 Cavendish Square Holdings BV v El Makdessi [2016] A.C. 1172 (the novel ratio of Dunlop was found in the widely neglected opinion of Lord Atkinson rather than in Lord Dunedin's which had become the locus classicus on the subject for a century).

28 A.W.B. Simpson, "The Common Law and Legal Theory" in A.W.B. Simpson (ed.), Oxford Essays in Jurisprudence: Second Series (Oxford 1973), 77, 88.

29 Levi, An Introduction to Legal Reasoning, 3-4.

30 G. Lamond, "Do Precedents Create Rules?" (2005) 11 Legal Theory 1.

31 (1863) 122 E.R. 309.

32 See A.W.B. Simpson, "Innovation in Nineteenth Century Contract Law" (1975) 91 L.Q.R 247, 270.

33 Taylor $v$ Caldwell (1863) 122 E.R. 309 (K.B.), 315.
} 
purpose of the parties becomes impossible. ${ }^{34}$ Blackburn J. himself did not take his decision as upending the old common law rule going back to Paradine $v$ Jane. ${ }^{35}$

Fast forward by a decade to Jackson $v$ Union Marine Insurance where the issue revolved around whether the delay of over half a year caused by the ship having run aground discharged a charter of the ship required for immediate dispatch to San Francisco. ${ }^{36}$ The majority opinion of Bramwell B. found the case analogous to Taylor while the dissenting opinion of Cleasby B. did not find it so. The key to their diverse approaches lies in how they framed Taylor. The dissenting opinion of Cleasby B. framed Taylor as a case of destruction of subject matter. Bramwell B.'s majority opinion framed Taylor by putting it into a category that would lend itself to be extended - namely, one where the teleological notion of the object of the parties came into play. This paved the path for Bramwell B. to see Taylor supported under the broader rationale of frustration of object. Once the rationale of frustration of object is seen to ultimately justify the outcome in Taylor, it was found good enough to justify the outcome in Jackson.

Later, in Krell $v$ Henry, ${ }^{37}$ where the issue was whether a contract was discharged when an event (the coronation) which formed the basis of the parties entering into it did not come to pass, Vaughan Williams C.J. repelled the defendant's argument (which harked back to Taylor) that the contracts could only be discharged for destruction of subject matter - by specifically pointing out that Jackson had "extended" Taylor analogically. It is only after Krell that "frustration of object" became cemented in English law as a ground for discharge of contract. In retrospect, Taylor being invoked as analogy for "frustration of object" might seem to a textbook-bound student to be an inescapable choice. But this would be to ignore the fact that there is no objective or neutral way of framing Taylor, and any way of doing so involves an element of choice. Nor can there be an assumption that the rationale underlying a source analogue must always necessarily be a broad one. English law, for instance, has consciously not extended "impossibility" and "frustration of purpose" cases to cases of "commercial impracticability" where the commercial purpose for which the contract is entered into is radically altered. By contrast, the Uniform Commercial Code (UCC) in the US has extended this line of cases to "commercial impracticability". 38 Someone inclined to endorse this might do so upon a framing of Jackson and Krell in a way that supports the rationale of "commercial impracticality". After all, it is not too far-fetched to extend "frustration of object" to the

\footnotetext{
34 Ibid., at 271 .

35 C. Macmillan, "Taylor v Caldwell (1863)" in C. Mitchell and P. Mitchell (eds.), Landmark Cases in the Law of Contract (Oxford 2008), ch. 6, 167, 201.

36 Jackson v Union Marine Insurance (1874) L.R. 10 C.P. 125.

37 Krell $v$ Henry [1903] 2 K.B. 740.

38 Uniform Commercial Code, s. 2-615.
} 
frustration of the "commercial objective" of the contract. It is, in fact, not even that far-fetched to frame Taylor in such a way as to read the rationale of "common object", "commercial object" or any other similarly broad rationale which can then be extended to a wide sweep of cases. Accordingly, Posner wearing his judicial hat, found the economic rationale of "risk transfer" underlying the frustration cases such as Taylor - which is then readily extendable to "commercial impracticability" cases. 39 There is little doubt that the drafters of the UCC too must in their deliberations have reasoned "analogically" from the existing law, but the key to this is to see the choice made by them to frame the past cases in a certain way. And it is as much of a choice which explains why no English court has framed these cases in a way that would enable them to use them as analogies to discharge contracts for "commercial impracticability".

When allowance is made for the invocation of distant analogies ${ }^{40}$ and the related phenomenon of invoking broadly couched rationales to extend a past decision to the case at hand, one finds that not only is there an ample leeway in how one frames a source analogue, but also in what one chooses to invoke as the source analogue in the first place. The greater the leeway gets, the stronger becomes the presumption against any normatively constraining judgments of similarity from past cases. But the true magnitude of the leeway available to a judge in analogical reasoning does not emerge clearly until one appreciates cases in the opposite direction where the courts have not extended a case analogically; even in circumstances that would seem "similar" to the greenest matriculand. These often remain hidden in plain sight simply because theory tends not to see them as deliberate choices related to analogical reasoning. But they are; and it is important that they are understood in those terms.

A good example of this phenomenon is found in how Rylands $v$ Fletcher has come to be treated by common law courts, particularly in the post-war period. In the Exchequer Chamber Blackburn J. held that anyone who brings on their land something not naturally there is liable for the damage caused by its escape, even if it was without their fault. ${ }^{41}$ If there was ever a case which had all the potential of becoming an engine for analogy creation, it was Rylands. In fact, by the early twentieth century, academic commentary had already paved the path for its wide invocation by pitching Rylands as supportive of an idea of "strict liability" for ultra-hazardous activities. ${ }^{42}$ But the subsequent history of tort law reveals the lengths to

\footnotetext{
39 Northern Indiana Public Service Co. v Carbon County Coal Co. 799 F.2d 265 (7th Cir. 1986). This an extension of Posner's extra judicial writing: see the discussion in S. Halpern, "Commercial Impracticability" (1987) 135 Pennsylvania Law Review 1123, 1161.

40 G. Lamond, "Analogical Reasoning in the Common Law" (2014) 34 O.J.L.S. 567.

41 (1865-66) L.R. 1 Ex. 265.

42 F.H. Newark, "Boundaries of Nuisance" (1949) 65 L.Q.R. 480, 488.
} 
which the courts went to avoid the seemingly easy path of extending Rylands.

In Read v Lyons, a munitions inspector in an ordinance factory suffered personal injuries from an exploding shell during manufacture. ${ }^{43}$ At first instance, Cassels J. found for the plaintiff by extending Rylands to cases regulating "ultra-hazardous" activities. Cassels J. also found that the case was analogous with cases falling under the scienter rule - liability for animals known to be dangerous - which too, he argued, could come within the ultra-hazardous principle of Rylands. On both counts, Cassels J.'s decision involved analogically extending Rylands to cases which did not directly fall within its scope. ${ }^{44}$ But the Court of Appeal reversed the decision - which was confirmed by the House of Lords. The House of Lords read the Rylands rule narrowly and found that the case did not fall within it. The primary ground on which they dismissed the claim was that the Rylands rule was not engaged since the injury had occurred on the premises of the defendant and there was no "escape". But it is interesting to note that, with the "rule" in Rylands not strictly being engaged, the House of Lords did nothing to extend Rylands to the case at hand either. In fact, Lord Macmillan specifically rejected the analogy of liability for personal injuries caused by dangerous animals (the scienter rule) which was found persuasive by Cassels J. in the court below. And Lord Porter noted that, if liability in Rylands which "was itself an extension" were to be extended further analogically, it would lead to "oppressive" results. ${ }^{45}$ In order not to extend Rylands analogically, the House of Lords consciously and deliberately framed it in very narrow terms. There were also considered dicta from the bench to the effect that personal injuries would not be actionable at all under Rylands. All this strongly indicates that the House of Lords in Read $v$ Lyons sought to frame Rylands narrowly, as a nuisance case. ${ }^{46}$ Since nuisance does not extend to personal injury, Rylands framed as a nuisance case, could not extend to personal injuries either. Later, in Transco plc $v$ Stockport $M B C,{ }^{47}$ the House of Lords expressly framed Rylands as a nuisance case and held that it could not therefore extend to cases of personal injury. Now, it is not at all obvious that Rylands is to be necessarily framed in these narrow terms. To consider an example from elsewhere in the common law world, the Supreme Court of India has extended Rylands to cases of liability for personal injuries caused by any "hazardous or inherently dangerous activity". 48

\footnotetext{
${ }^{43}$ Read v Lyons \& Co. Ltd. [1947] A.C. 156.

44 A fact noted by Lord Macmillan, ibid., at 171.

45 Ibid., at 178 (quoting with approval Lindley L.J.'s opinion from Green v Chelsea Waterworks Company (1894) 70 L.T. 547, 549).

46 See Newark, "Boundaries of Nuisance", 488. For dicta to this effect from the judgment, see Read v Lyons [1947] A.C. 156, 173 (Lord Macmillan).

47 Transco plc v Stockport Metropolitan Borough Council [2004] 2 A.C. 1.

48 M.C. Mehta v Union of India [1987] 1 S.C.R. 819, 844 (Supreme Court of India).
} 
Another decision that illustrates this consciously narrow framing of Rylands $v$ Fletcher is the decision of the Court of Appeal in Stannard v Gore. ${ }^{49}$ The defendant stored a large number of rubber tyres on their premises. The tyres caught fire, through no fault of the defendant, and the fire spread to the neighbour's property where it caused damage. The question was whether Rylands $v$ Fletcher would support imposition of liability in the case. An adherent of the standard picture to whom past cases normatively extend themselves might suppose that, even if one did not subsume this case within the Rylands rule, it would be a tall order indeed to block analogising from it to a liability in the case at hand. There are multiple points of similarity between this case and Rylands which seem to cry out for an extension of Rylands. But here, again, not only did the Court of Appeal find that the case could not be subsumed within Rylands, they did not extend it analogically either. The court read Rylands as requiring that the very thing brought into the land ought to escape - which in this case would be tyres. The fire from burning tyres escaping would not do. One could well argue that this is the equivalent of framing Donoghue $v$ Stevenson as a case confined to harmful fauna in opaque containers.

What the trajectory of the foregoing illustrations establishes is that there is no normatively constraining pathway of extending the past case (the so-called "source") analogically. And it follows that analogical reasoning cannot be the extending of a past case guided by some normative notion of similarity. A prior, independent choice is necessarily involved in what one picks as an analogy and how one frames it. That choice being a hallmark of analogical reasoning, any plausible theoretical account of analogical reasoning had better explain it. However, there is none forthcoming in standard accounts of analogical reasoning. Indeed, admitting a prior independent choice risks driving a coach and four through the standard accounts of analogical reasoning since it would mean conceding the absence of any normative constraint by the lights of the truth-based model of normativity presupposed by the standard accounts. As we shall find in the objection that follows the present one, this feature of analogical reasoning can be explained by the fact that the direction of fit of analogical reasoning is the reverse of what the standard picture assumes.

\section{B. Rhetoric and Direction of Fit}

The argument that analogical reasoning is rhetorical reasoning is a familiar one, but underlying it is a deeper objection about the direction of fit of analogical reasoning, which does not get articulated clearly enough. Let us first consider the familiar "rhetoric" argument. ${ }^{50}$ Posner, its foremost proponent,

\footnotetext{
49 Stannard v Gore [2012] EWCA Civ 1248, [2014] Q.B. 1.

50 Posner, Analogy, 762; Posner, Problems, 92.
} 
argues that standard accounts of analogical reasoning at best capture how judges "talk", but that is far from how judges actually "think". ${ }^{51}$ As Posner puts it, the past case is merely "information" which the judge is at liberty to use in any way she likes. The judge knows at the outset what she seeks to achieve, and an analogy or example is invoked as a means to persuade the interlocutor to adhere to the speaker's argument. Posner's critique, however, presupposes and points to - if only dimly - a deeper underlying worry about standard accounts of analogical reasoning, of which, the rhetorical point is only the sequitur. That deeper worry is that standard accounts of analogical reasoning have got the direction of fit between the so-called "source" analogue and the "target" analogue all scrambled up. Posner faintly hints at this by invoking Hume in support:52

If direct laws and precedents be wanting, imperfect and indirect ones are brought in aid; and the controverted case is ranged under them by analogical reasonings and comparisons, and similitudes, and correspondencies, which are often more fanciful than real. In general, it may safely be affirmed that jurisprudence is, in this respect, different from all the sciences; and that in many of its nicer questions, there cannot properly be said to be truth or falsehood on either side ... the preference given by the judge is often founded more on taste and imagination than on any solid argument. ${ }^{53}$

To appreciate the full import of Hume's argument on analogical reasoning, it would be helpful to note the striking parallels here with Hume's own account of morality. Hume argued that ethical judgments are not discoverable by reason and hence are not truth-apt, which is to say, they are not to be assessed in terms of truth or falsehood. Rather, these were expressions of attitudes and emotions - which are mental states not assessable in terms of truth or falsehood. ${ }^{54}$ Hume's famous motto was that "reason" is a "slave of the passions". ${ }^{55}$ What Hume does here is propose a "reverse direction of fit" of moral judgments to the one proposed by truth-based models. While truth-based models have a "world-to-mind" direction of fit, the Humean one is based on its reverse: a "mind-to-world" direction of fit. The upshot of this Humean move is that the point of ethical argument is persuasion, and not the invocation of some truth. ${ }^{56}$ This is doubly locked in place by Hume's picture of psychology on which world-to-mind judgments (e.g. belief about some truth), are motivationally inert while mind-to-world

\footnotetext{
51 Posner, Analogy, 765.

52 Posner, Problems, 95-96.

53 D. Hume, Enquiries Concerning Human Understanding and Concerning the Principles of Morals, 3rd ed., by P.H. Nidditch (ed.) (Oxford 1975), 308-09 (emphasis added). Cited by Posner, ibid.

${ }^{54}$ F. Jackson, G. Oppy and M. Smith, "Minimalism and Truth Aptness" (1994) 103 Mind 287.

55 D. Hume, A Treatise of Human Nature, by L.A. Selby-Bigge and P.H. Nidditch (eds.) (Oxford 1978), 415 .

56 A modern classic building on this Humean view is B. Williams, Ethics and the Limits of Philosophy (London 1985).
} 
judgments (attitudes or emotions) are motivationally laden. ${ }^{57}$ As we shall see in the following section, persuasion and rhetoric are salient to Hume's account of ethics.

Hume's parallel argument about analogical reasoning is that the direction of fit between the so-called "source" and "target" analogue is the reverse of what the standard accounts of analogical reasoning suppose. The decision to invoke a source analogue is not informed by any normative constraint (it is not prone to truth or falsehood, as Hume puts it) put in place by the source analogue itself, but rather it is the prior, independent decision (preference "founded on taste and imagination", as Hume puts it) to reach a certain result which informs the choice to frame the source analogue in a certain way. That prior, independent decision having been made, the so-called "source" analogue gets chosen, framed and invoked to justify it. The choice of source analogue is at the service of whatever end the reasoner has in mind. It will be recalled that in contrast to this Humean picture, standard accounts of analogical reasoning presuppose a truth-based model of normativity on which target analogues involve normatively constraining judgments of similarity with past decisions. Although Hume himself does not take the step here - but Posner does - the logical sequitur of Hume's views on the direction of fit of analogical reasoning is that it is a form of rhetorical reasoning where a past case is picked for its value as a rhetorical counter to persuade the interlocutor about the acceptability of a prior, independent decision on the substance of the case. The full implication of these arguments would be, in effect, to reverse the picture of analogical reasoning found on standard accounts. The lesson at the heart of Hume's argument revolving around direction of fit is that the truth-based model of normativity, which is presupposed by standard accounts of analogical reasoning, is a mischaracterisation of analogical reasoning.

Now, Posner makes the familiar rhetorical point only to write off the whole enterprise of analogical reasoning. This is the natural denouement of Posner's rhetoric-based objection. Something that Posner himself never specifically spells out in so many words is his supposition that since what is at play here is rhetorical reasoning, it is unfathomable how it should ever be normatively constraining in any manner. But this sceptical conclusion only follows if one supposes that the truthbased model of normativity provides the only plausible explanation of analogical reasoning. If this were to be the case, any piece of rhetorical reasoning - in which direction of fit runs in the "reverse", which is to say, from the present case to the past case - would eo ipso be without normative constraints. As we shall see in the following section, this is far from being the case.

${ }^{57}$ M. Smith, The Moral Problem (Oxford 1994), 7-9. 


\section{Polycentricity AND Motivational NoRmativity}

If the truth-based model of normativity does not account for analogical reasoning, is one constrained to throw in the sponge (which sceptics like Posner do) and concede that analogical reasoning cannot possibly be accommodated under any normative model? In other words, can one portray analogical reasoning as a normative enterprise at all if one concedes that there are no normative constraints imposed by the past cases in the process of analogical reasoning (in a manner supposed by the standard picture) and that there is an inevitable element of choice involved in framing past decisions? Whether one is constrained to admit at this point that analogical reasoning is not a normative exercise depends on whether one is able to situate the existing practice of common law reasoning within the rubric of an alternative normative model that is not a truth-based one. In what follows, we do precisely that by sketching a motivational model of normativity based on a polycentric account of analogical reasoning in the common law which, it will be argued, is an alternative to the truth-based model. Despite its reverse direction of fit (i.e. not being truth-based), it will be argued that there are normative constraints on this model. To be sure, the choice of how to frame an analogy is not constrained by the analogues themselves. But there will be other robust constraints found on this alternative account which keep the process normatively bounded. The key to understanding this account and model of normativity underlying it is the idea of polycentricity.

\section{A. The Idea of Polycentricity}

Polycentricity is an idea due to the polymath Michael Polanyi which he gleaned, to a significant extent, from the workings of the common law. ${ }^{58}$ In abbreviated form, the idea comes to this. A polycentric system of decision-making (such as the common law) involves a number of decision makers who go about their task of making decisions by anticipating what is likely to pass muster with the community. ${ }^{59}$ And having thus arrived at a decision, then seek to persuade the community of decision-makers by justifying the decision at hand by falling back on previously decided cases. Polycentric decision-making can thus be understood as a two-pronged process. The first prong is epistemological, involving as it does, discovery,

\footnotetext{
58 Polanyi's account of polycentricity is found in the following works: The Logic of Liberty: Reflections and Rejoinders (Chicago 1951), Personal Knowledge (London 1972) and Tacit Dimension (New York 1966).

59 In the legal case, for Polanyi, the community to be persuaded was that comprising other judges and juries: Polanyi, Logic of Liberty, 165-66. To this should be added the legal profession, and possibly, as John Bell suggests, the academia and students of law too: J. Bell, "The Acceptability of Legal Arguments" in N. MacCormick and P. Birks (eds.), The Legal Mind: Essays for Tony Honoré (Oxford 1986), 53.
} 
while the second prong is rhetorical since it involves justification of the decision.

Lon Fuller borrowed the term "polycentricity" from Polanyi and used it as a rubric to discuss an aspect of common adjudication, ${ }^{60}$ but Fuller's point is rather different from Polanyi's. ${ }^{61}$ Although Fuller's idea of polycentricity (which has little to do with Polanyi's idea of polycentricity) has had some traction among legal scholars, Polanyi's idea remains largely neglected. ${ }^{62}$ Here, our attention will be on Polanyi's idea of polycentricity not Fuller's. In sharp contrast to its fortunes in legal scholarship, Polanyi's idea of polycentricity has left an indelible mark on many other areas of thought including economics (ranging from Friedrich Hayek's idea of the working of spontaneous orders to Elinor Ostrom's idea of the regulation of the commons) and philosophy of science (Thomas Kuhn's notion of scientific paradigms, which is discussed later). One would have to put this underappreciation of Polanyi's idea of polycentricity (hereafter "polycentricity") in legal scholarship down as somewhat of a missed opportunity, for polycentricity has the potential to deliver illuminating theoretical insights on the workings of the common law. This is all the more so because Polanyi gleaned the idea, in large part, from the working of the common law. Elsewhere, I have sought to sketch out some potential insights polycentricity might hold for theory construction in the common law. ${ }^{63}$ Here, we will see how polycentricity helps us appreciate analogical reasoning in the common law. And, more significantly, we will see how polycentricity holds the key to showing us that even if past cases are not normatively constraining in analogical reasoning - and that there is an inevitable element of choice in selecting and framing analogies - it could nonetheless yield a robustly normative system through other means. This is thanks to the motivational normative model underlying the polycentric account which shall be seen to emerge as an alternative to the truth-based model of normativity.

\section{B. Epistemology of Polycentric Judging}

For better appreciating how polycentricity works in the law, it might be useful to begin with one of Polanyi's simpler examples demonstrating how the most elementary of pricing operations in the market display the epistemological (anticipating how the market will react) and rhetorical (pricing it such as to persuade the buyer to purchase) prongs of his polycentric theory.

\footnotetext{
${ }^{60}$ L. Fuller, "Forms and Limits of Adjudication" (1978) 92 Harvard Law Review 353.

${ }^{61}$ For a discussion of the difference between Fuller's and Polanyi's ideas of polycentricity, see S. Swaminathan, "What the Centipede Knows: Polycentricity and 'Theory' for Common Lawyers" 40 (2020) O.J.L.S. 265.

${ }^{62}$ Fuller's idea has received hard knocks from J.W.F. Allison, "Fuller's Analysis of Polycentric Disputes and the Limits of Adjudication" [1994] 53 C.L.J. 367, and J. King, Judging Social Rights (Cambridge 2012).

63 This follows Swaminathan, "What the Centipede Knows".
} 
A considerable chunk of Polanyi's oeuvre was dedicated to elucidating the epistemological prong of polycentricity - his most lasting contribution perhaps being the idea of "tacit knowledge". ${ }^{64}$ Knowledge that one can use proficiently, albeit without being able to state it in the form of propositions is "tacit knowledge". It is found in activities ranging from learning swimming to mastering a language - although there are important differences between knowledge acquisition in the two cases. While the mastering of swimming is a solitary activity, mastering a language involves a communal element. As Michael Oakeshott aptly described it, knowledge of language should not be seen as a mastery of a fixed set of utterances, but rather, as the ability to anticipate what is likely to pass muster with a group of language users. ${ }^{65}$ This point is well illustrated by an anecdote related by Brian Simpson - which, as we will find, is of a piece with the legal case. When faced with an objection from a copy editor that the word "inruption" cannot be used in the manuscript since it did not find mention in the Oxford English Dictionary, Simpson replied: "[T] he word was properly formed from Latin roots, 'in' and 'rumpere' (as the copy editor conceded) and, once it appeared in my book, would at once exist as an English word ... Once in print 'inruption' could then be recorded in the Oxford dictionaries, and, as if by magic, become correct English." 66

The deeper message underlying Simpson's anecdote, as he himself explains it, is that evolution of the English language is akin to the evolution of the common law. ${ }^{67}$ At the heart of the evolution of both is tacit knowledge - although Simpson himself does not himself use the idiom of "tacit knowledge". An adept user of language learns to anticipate which coinage is likely to pass muster with the community of language users. This is the reason the neologism "Covfefe" 68 is unlikely to ever be mot juste for anything sensible, unlike Gustave Flaubert's invention of the latter phrase. Just like an adept language user, a common law judge learns to anticipate what is likely to pass muster with the legal community. Elsewhere, Simpson has described how this works, by sketching the picture of the common law as the collective intuitions of the legal profession. ${ }^{69}$ It might be more aptly described as the collective tacit knowledge of the profession. It involves

${ }^{64}$ Polanyi, Personal Knowledge; Polanyi, Tacit Dimension. Tacit knowledge is know-how one can proficiently use, without being able to state it in propositional form.

${ }^{65}$ M. Oakeshott, On Human Conduct (Oxford 1975), 120.

${ }^{66}$ A.W.B. Simpson, "The Reflections of a Craftsman" in M. Andenas and D. Fairgrieve (eds.), Tom Bingham and the Transformation of the Law: A Liber Amicorum (Oxford 2009), 193-205, 209.

${ }^{67}$ Ibid. This tallies with the classical common law position. As Michael Lobban argues, "for Hale, law (like language) was the product of institution rather than abstract reason": M. Lobban, "Thomas Hobbes and the Common Law" in D. Dyzenhaus and T. Poole (eds.), Hobbes and the Law (Cambridge 2012), 63.

68 A neologism coined, perhaps unwitting, by businessman, reality television star and 45th president of the US, Donald Trump.

69 See Simpson, "The Common Law and Legal Theory", 95. A similar view is also found in J.H. Baker, The Law's Two Bodies: Some Evidential Problems in English Legal History (Oxford 2001), 64-70. 
knowing the apt response to the case at hand; the apt response, in turn, is to be understood as an anticipation of what response is likely to pass muster with the community of decision makers. Simpson's argument is that through years of training, the common lawyer tends to internalise the gaze of the professional group and its sensibility of what is the apt response in a given case. ${ }^{70}$ By the time they are elevated to the bench - typically drawn from senior members of the bar - they tend to become experts at anticipating what is likely to pass muster with the legal community. ${ }^{71}$ Thomas Kuhn argued that scientific research too works in the same way with the "tacit knowledge" in this case being held up by the collective gaze of the peer group of researchers. ${ }^{72}$

The legal practitioner's skill lies in anticipating - through a similar process of tacit knowledge - what approach a judge is likely to take in a given case. ${ }^{73}$ It is this simple insight which seems to be at the core of Oliver Wendell Holmes Jr.'s notion of the law as a "prophecy", ${ }^{74}$ which tends rather unfairly, one might add - to be given short shrift by legal philosophers. ${ }^{75}$ What Holmes suggests makes sense of why legal opinions are typically couched in the language, not of what the law "is", but rather in terms of how the court is "likely" view a matter. This also ties in with Holmes' oft-quoted but poorly appreciated idea of "experience", which was very similar to the idea of tacit knowledge. ${ }^{76}$ The word "experience" has this inherent ambiguity since the Greek emperikos (experience), to which it traces its provenance, shares the same etymological root as empeiros which means "experienced" in the sense of being "skilled". This image of the common law is one that fits in quite nicely with Polanyi's polycentric picture. Historically, the idea of "artificial reason" going back to Coke - deriving from an artifex or craftsman - lends itself to be understood in these terms. ${ }^{77}$

70 Simpson, "The Common Law and Legal Theory", 95.

71 As Raz notes, the English bar is already a fairly homogenous bunch to begin with: Raz, Authority of Law, 180.

72 T. Kuhn, The Structure of Scientific Revolutions, 2nd ed. (Chicago 1970), 191 (following Polanyi, Kuhn specifically invokes "tacit knowledge").

73 Bell, "The Acceptability of Legal Arguments", 57.

74 O.W. Holmes Jr., "The Path of the Law" (1897) 10 Harvard Law Review 457.

75 H.L.A. Hart, The Concept of Law, 2nd ed. (Oxford 1994), 39, 286.

76 L. Menand, "Bet-Tablitarianism" (1996) 215 The New Republic 47 (Holmes thought that experience involved "insight" and "special knowledge"). The earliest systematic proponent of the idea of tacit knowledge seems to have been J. Dewey, Human Nature and Conduct (New York 1922). Later proponents include M. Heidegger, Being and Time, translation by J. Macquarrie and E. Robinson (New York 1962) (Heidegger describes it as "ready-to-hand" or Zuhanden); G. Ryle, The Concept of Mind, 2nd ed. by J. Tanney (London 2009), 14 48; and F. Hayek, Law, Legislation and Liberty, vol. 1 (London 1982), 11.

77 A. Cromartie, Thomas Hobbes: A Dialogue between a Philosopher and a Student of the Common Laws of England (Oxford 2005), xxiii; U. Lewis, "Sir Edward Coke: His Theory of 'Artificial Reason' as Context for Modern Legal Theory" (1968) 84 L.Q.R. 330, 337; see also Swaminathan, "What the Centipede Knows", 276. 
Depictions of the common law consistent with this idea of tacit knowledge can also be found in the writings of Friedrich Hayek, ${ }^{78}$ John Baker, ${ }^{79}$ Anthony Kronman, ${ }^{80}$ John Bell, ${ }^{81}$ Stanley Fish ${ }^{82}$ and, more recently, in the work of Hanoch Dagan. ${ }^{83}$ Although Karl Llewellyn ${ }^{84}$ neither systematically developed the idea nor placed it in a broader philosophical account, there are elements in his account that accord with this idea of tacit knowledge. The idea is also compatible with those who tend to view common law judging as involving a form of "aesthetic sense", 85 practical wisdom or techne 86 - just so long as one bears in mind the communal element involved in its exercise, which is not necessarily present in all examples of practical wisdom or phronesis. ${ }^{87}$ As we shall see later, the communal nature of the tacit knowledge is the all-important element in the model of normativity underlying polycentric systems. Relying upon such tacit knowledge, one might anticipate - although not anywhere near as skilfully as a practitioner, let alone a judge - that English courts are presently unlikely to extend the "strict liability" regime inaugurated by Rylands. Seen thus, the judicial choice underlying framing Rylands narrowly and not extending it in a succession of cases becomes transparent. No amount of staring at cases or plotting out the lines of similarity emanating from them can replace this skill in anticipation.

Adherents of standard accounts of analogical reasoning like Weinreb, who emphasise the involvement of skill in the process, dimly touch upon something vital, but stop short of coherently articulating it, given the model of normativity their accounts are enmeshed with. On these accounts, legal skill ends up as little more than a parlour trick as its principal task is to connect past cases to present ones through likeness and similarity. ${ }^{88}$ Seen thus, it becomes akin to a "matching of colours", to use Benjamin Cardozo's memorable phrase. ${ }^{89}$ But this is to mischaracterise what is understood as acquisition of skill in the law. The common law has a selfconscious conception of skill (artificial reason) going back all the way to

\footnotetext{
78 Hayek, Law, Legislation and Liberty, 117.

79 Baker, Law's Two Bodies, 64-70.

80 A. Kronman, The Lost Lawyer: Failing Ideas of the Legal Profession (Cambridge, MA 1995).

81 Bell, "The Acceptability of Legal Arguments", 55.

82 S. Fish, Doing What Comes Naturally (Durham, NC 1989) (Fish invokes Polanyi's idea of tacit knowledge).

83 H. Dagan, “The Real Legacy of American Legal Realism” (2018) 39 O.J.L.S. 123 (building on Kuhn's idea of scientific paradigms - which in turn, is an iteration of Polanyi's polycentricity).

84 K. Llewellyn, The Common Law Tradition: Deciding Appeals (Boston 1960), 121 (Llewellyn spoke of "horse sense" and "folk ways").

85 K. Gray and S.F. Gray, "The Rhetoric of Realty" in J. Getzler (ed.), Rationalizing Property, Equity and Trusts: Essays in Honour of Edward Burn (Oxford 2003), 234; D. Edlin, Common Law Judging (Ann Arbor 2016)

86 T. Viehweg, Topics and Law: A Contribution to Basic Research in Law, translated by W. Cole Durham Jr. (Frankfurt 1993), xviii.

87 See A. Amaya, "Exemplarism and Judicial Virtue" (2013) 25 Law and Literature 428, 431.

88 Posner, Problems, 93; MacCormick, Legal Reasoning and Legal Theory, 166.

89 Cardozo, Nature of the Judicial Process, 20.
} 
Coke. This is best understood as sensibility which guides a judge to what is the apt substantive decision in the case with reference to what is likely to pass muster with the group.

This may be as good a place as any to enter a caveat about the nature of the tacit knowledge being discussed here. Three factors moderating the efficacy of tacit knowledge may be noted. First, as Kuhn argued, tacit knowledge explains how "normal science" works, but there are also periodic ruptures brought about by "scientific revolutions" which tacit knowledge cannot anticipate. ${ }^{90}$ Likewise, as Dagan points out, there are going to be paradigm altering cases which cannot be readily anticipated through tacit knowledge. ${ }^{91}$ Arguably, the decision of the Supreme Court in the recent "prorogation" case could be thought to be of such a kind. ${ }^{92}$ Such cases excepted, it would not be rash to say that tacit knowledge can be counted upon to do its job reliably - which is to say, more than "eight times out of ten". ${ }^{93}$ Secondly, tacit knowledge is better at anticipating what a bench will hold rather than what an individual judge will. There will be cases where an individual judge, despite being mindful of the result dictated by tacit knowledge, might choose to chart a different course - as it is typically the case in dissenting opinions. However, it is important to note that these are viewed by the legal community as deviations which are policed by force of the collective professional gaze that holds up tacit knowledge. Commonly, this takes the form of thwarting the "reformist" agendas by reinforcing the "orthodoxy" - as Lord Mansfield repeatedly faced. ${ }^{94}$ In rare cases, it could also take the extreme form of the kind of ostracism Lord Atkin had to endure after his dissent in Liversidge $v$ Anderson. ${ }^{95}$ Thirdly, from the practitioner's point of view, what tacit knowledge is likely to reveal more reliably is the result or relief in the case rather than the route through which it is reached. A good number of Lord Denning's ostensibly radical decisions reached perfectly predictable, even anodyne, results in the case at hand - on which he was in agreement with the rest of the bench albeit by reasoning to it through the use of a principle thought too broad or wide by the others on the bench. Lloyds Bank v Bundy ${ }^{96}$ (where he introduced the doctrine of "inequality of bargaining power") and Butler

90 Kuhn, The Structure of Scientific Revolutions, 92-98.

91 Dagan, "The Real Legacy of American Legal Realism", 135.

92 R. (Miller) v The Prime Minister; Cherry v Advocate General for Scotland [2019] UKSC 41, [2020] A.C. 373.

93 J.W. Harris, Legal Philosophies (Oxford 2011), 100 (noting the working of Llewellyn's "folkways").

94 Examples of this abound. Perhaps the most notable is Lord Mansfield's attempt to abolish the centuries-old consideration requirement in Pillans $v$ Van Meirop (1765) 97 E.R. 1035, which was promptly scuppered by the House of Lords in Rann v Hughes (1778) 2 E.R. 18.

95 [1942] A.C. 206. A judge who routinely strays away from the demands of tacit knowledge is likely to be classified as a "rebel" and ultimately a "rogue". The chequered career of Justice Henry McCardie, which also witnessed an unprecedented open personal rebuke from an appellate judge (Lord Scruton) is a prime example: see A. Lentin, Mr. Justice McCardie: Rebel, Reformer and Rogue Judge (Newcastle 2016).

96 [1975] Q.B. 326. 
Machine Tools v Ex-Cell-O Corporation ${ }^{97}$ (where he proposed abolishing orthodox doctrines of "offer" and "acceptance" as a rubric to understand contract formation) are good examples of this.

\section{Rhetoric and Justification}

Once the judge anticipates or knows (guided by tacit knowledge) the apt response in the case at hand, we move to the next step of the process which is that of persuasion. ${ }^{98}$ Here, the judge falls back on the stock of past responses and seeks to justify the decision in the case at hand by showing how it is similar to a previous case. Past cases then, are used as rhetorical counters which are meant to persuade the interlocutors about the decision in the present case. Although Hume himself never explicitly drew out this connection, it follows from Hume's account of the common law - touched upon briefly in Section 2 - that "analogical reasoning" is a form of rhetorical reasoning. To help us understand how a rhetorical account of law and persuasion follows from Hume's starting premises, we would do well to cast a glance at the nineteenth century Scottish philosopher, Joseph Campbell's Philosophy of Rhetoric in which he developed a theory of rhetoric based on a Humean theory on moral values. ${ }^{99}$ At the heart of persuasion and rhetoric, for Campbell, was the Humean idea of attraction and association among impressions. The central function of rhetoric was the transfer of force from one impression to another by relying on resemblance and contiguity. ${ }^{100}$ Persuasion would be more effective if built upon relations of resemblance and similarity with already accepted opinions. ${ }^{101}$ Perelman has very similar things to say on the persuasive value of resemblance and similarity, albeit without basing it on a Humean account of practical reasoning. ${ }^{102}$

Seen thus, analogical reasoning in the common law is a form of rhetorical reasoning in which past decisions are used as rhetorical counters in a discursive enterprise to persuade the legal community. Once the judge knows through tacit knowledge what the apt response in a given case is, the next step is to "justify" the decision in these rhetorical terms by using past cases which will give traction to its persuasive value. In the context of analogical reasoning, this means extending a past decision. As discussed earlier, this involves framing the case in a certain way so it may provide rhetorical support to the conclusion reached in the case at hand.

${ }_{97}^{97}$ [1979] 1 W.L.R. 401 (C.A.).

98 A prominent example of this, a two-stage process (differentiating "discovery" and "justification"), is R. Wasserstrom, The Judicial Decision (Palo Alto 1961).

99 G. Campbell, Philosophy of Rhetoric (New York 1868).

100 L.F. Bitzer, "Hume's Philosophy in George Campbell's Philosophy of Rhetoric" (1969) 2 Philosophy and Rhetoric 139, 153.

101 Hume supports this idea of transfer of moral imagination: Hume, Enquiries, 290.

102 C. Perelman and L. Olbrechts-Tyteca, The New Rhetoric (Notre Dame 1973), 107, 219. 
This account, therefore, makes sense of the leeway found available to the judge in framing an analogue. On this picture, a judge approaches past cases (putative analogues), having already made a choice about how to frame them - whether in wide or narrow terms. This makes analogical reasoning a part of the "justification", rather than the process of "discovery". This is something sceptics of analogical reasoning like Posner harp on, as if it could be nothing but a fatal flaw. On the alternative account being sketched here, it is seen transformed as a part of the polycentric account.

The term "rhetoric" - which is depicted as an important element in analogical reasoning in this alternative account - is likely to set off fog horns up and down the ranks of modern legal theorists. For some sceptics, the worst thing they could possibly say about analogical reasoning is that it is nothing more than rhetorical reasoning, tout court. And that is supposed to be a knock down argument against analogical reasoning. As we have seen earlier, Posner makes this argument against analogical reasoning. Lest the modern pejorative association of the term colour its proper appreciation, it is important to bear in mind that rhetoric was once a crucial constituent of the philosophers' repertoire. Isocrates, a contemporary of Socrates - and author of Antidosis and Aeropagiticus - made persuasion and rhetoric the mainstays of his philosophy. ${ }^{103}$ It might be noted parenthetically that the idea of scattered rationality plays an important part in Polanyi's idea of polycentricity. And Polanyi's inspiration for the idea of scattered rationality was John Milton's idea of the "scattered" statue of truth in Aeropagitica, named after Isocrates' work. ${ }^{104}$ As we shall argue later in this section, the idea of scattered rationality supports rhetoric and persuasion. Aristotle's deep interest in rhetoric should be seen against this historical backdrop, as should the importance given to it by Roman philosophers, Cicero and Quintilian - all of which makes Plato's polemic against rhetoric in his dialogues, Gorgias and Phaedrus, somewhat of an outlier in the ancient philosophical world. This is, no doubt, a far cry from modern philosophical trends where "rhetoric" itself has become a pejorative term. Albert Jonsen and Stephen Toulmin have retraced the trajectory of that downfall by showing us how rhetoric continued to be regarded as a respectable philosophical discipline until the Enlightenment and Blaise Pascal inaugurated much of the negativity now associated with the term. ${ }^{105}$

Returning to the greatest philosophical backer of the idea, Aristotle defined "rhetoric" as discovery of the available means of persuasion. ${ }^{106}$

103 See Isocrates, Antidosis, vol. II, by G. Norlin (ed.) (Cambridge, MA 1929), 181-367.

104 Polanyi, Logic of Liberty I, 88; J. Milton, Aeropagitica, by J.W. Hales (ed.) (Oxford 1932), 43.

105 For a discussion of the reasons for the downfall of rhetoric as a philosophical discipline, see A. Jonsen and S. Toulmin, Abuse of Casuistry: A History of Moral Reasoning (Berkeley 1988).

106 Aristotle, The Art of Rhetoric, by H.C. Lawson Tancred (ed.) (London 1991), 1355b. 
For Aristotle, rhetorical reasoning pertains to reasoning from endoxa or accepted opinions. ${ }^{107}$ These formed the basis for topoi (topics) or common places (also the title of Aristotle's work Topics), which were widely accepted points that a speaker reasoned from. ${ }^{108}$ The structure of such argument involved showing how the case at hand was similar to a past case and hence ought to be accepted. ${ }^{109}$ This form of argument formed a crucial component in Greek and Roman legal cultures. ${ }^{110}$ And it forms an important part of the common law tradition.

As Theodore Viehweg notes, it is no accident that it is the English term for Aristotle's endoxa, namely "opinion", which is "still used to characterize judicial decisions". ${ }^{111}$ Rhetorical learning was once an important part of the common lawyer's training and, until the birth of modern university legal education, late in the nineteenth century, law was regarded a subdivision of rhetoric. ${ }^{112}$ Rolle's Abridgment, a long-standing mainstay of common law literature was nothing more than Sir Henry Rolle's topoi or common place book. ${ }^{113}$ The claim that the common law is best understood in terms of topoi and rhetoric is hardly a novel one. It provides the backdrop for Viehweg's magisterial Topics and Law; and ties in with Hans-Goerg Gadamer's claim that common law reasoning is rhetorical. ${ }^{114}$ It was also Julius Stone's view that common law reasoning is a form of rhetorical reasoning, with past cases taking the place of topoi. ${ }^{115}$ In a similar vein, Fish postulates "persuasion" as the "goal" of judging. ${ }^{116}$ The novel theoretical move proposed here would be to place this rhetorical understanding of the common law within a sound model of normativity which has robust normative constraints in place. We now turn to see what this model of normativity looks like.

107 E. Bodenheimer, “A Neglected Theory of Legal Reasoning” (1969) 21 Journal of Legal Education 373.

108 C. Rapp, “Aristotle's Rhetoric" in E.N. Zalta (ed.), The Stanford Encyclopedia of Philosophy, Spring 2010 ed. (Paolo Alto 2010), available at https://plato.stanford.edu/archives/spr2010/entries/aristotlerhetoric/ (last accessed 4 April 2021).

109 Aristotle, Rhetoric, 1357b: "[Example] is related neither as the part to the whole, nor as whole to the part, nor as the whole to the whole, but as part to part, as like to like." The typical use of exemplary reasoning, as Aristotle puts it, is when what is invoked as example is a "known case" which is "more familiar" to the interlocutor. Although the term analogical reasoning is now commonly used to describe this process, as a number of scholars including Levi, Perelman, Postema and Brewer note, it is "exemplary reasoning" in the strict sense (and Aristotle too understood it as such). Aristotle's definition is also used by Bracton who describes it as "similubus ad simila": Postema, " $A$ Similibus ad Similia", 102.

110 M. Frost, Introduction to Classical Legal Rhetoric: A Lost Heritage (Abingdon 2005).

111 Viehweg, Topics and Law, xxiii.

112 Ibid., at xv, xxix. See A.D. Boyer, "Sir Edward Coke Ciceronianus: Classical Rhetoric and the Common Law Tradition" (1997) 10 International Journal for the Semiotics of Law 3.

113 A.W.B. Simpson, "The Rise and Fall of the Legal Treatise: Legal Principles and the Forms of Legal Literature" (1981) 48 University of Chicago L.R. 632, 640.

114 A. Hutchinson, "Work-in-Progress: Gadamer, Tradition and the Common Law" (2000) 76 Chicago Kent Law Review 1015.

115 J. Stone, Precedent and Law (Sydney 1985), 101.

116 Fish, Doing What Comes Naturally, 237. 


\section{Motivational Model of Normativity}

Hume opens An Enquiry Concerning Human Understanding by adumbrating two "manners" or "species" of philosophical enterprise. ${ }^{117}$ The one model envisages the task of moral philosophy as that of informing interlocutors. The other model envisages the task as that of motivating them. The one model takes moral philosophy as a matter of "speculation", the chief task of which is to expound the "foundations of morals" which it does, by discovery of standards. The other takes us as "active beings" motivated by "taste and sentiment" and hence takes philosophy as aiming for "moulding the heart and affections". On the former model, normativity or bindingness is a matter of our judgments conforming to some objective or mind-independent standards. As such, our response to or grasp of them is truth-apt, which is to say, capable of being true or false in relation to these standards. By contrast, on the latter model, bindingness or normativity of morality is nothing but the motivational pull exerted by a moral judgment. ${ }^{118}$ On this model, the interlocutor and motivating her take centrality. These models are the truth-based and motivational models of normativity, respectively. Hume himself was sympathetic to the motivational model of normativity. It should be readily apparent why this model of normativity naturally ties in with rhetoric - the principal aim of which is to seek motivational traction with the interlocutor. As Pierre Hadot shows us, the motivational model of normativity was crucial to "ancient philosophy" since much of it was about "transforming" the interlocutor. ${ }^{119}$ Aristotle's Rhetoric works on this model, as did Campbell's Humean theory of rhetoric.

Translated to the case of analogical reasoning, the two models of normativity come to this. The truth-based model has it that there is an objectively correct notion of similarity or likeness which the decision maker is responsive to in extending past cases. And it has it that invocations of analogy are truth-apt in relation to those objective notions of similarity or likeness. Standard accounts of analogical reasoning presuppose the truth-based model of normativity. These objective notions of similarity or likeness are the normative constraints on this model. By contrast, the polycentric account of common law reasoning presupposes a motivational model of normativity. On this model of normativity, decision-making seeks to be persuasive, which is to say, to have motivational traction in the practical reasoning of the interlocutor. On the polycentric model, a decision maker seeks to anticipate what is likely to be persuasive to the community. This

117 Hume, Enquiries, 5-6. This is explored in S. Swaminathan, "Dicey and the Brick Maker: An Unresolved Tension between the Rational and the Reasonable in Common Law Pedagogy" 40 (2019) Liverpool Law Review 203.

118 L. Russell, "Two Kinds of Normativity: Korsgaard v. Hume" in C. Pigden (ed.), Hume on Motivation and Virtue (Basingstoke and New York 2009), 208-09.

119 P. Hadot, What Is Ancient Philosophy? (Cambridge, MA 2002), 87. 
leads to a form of scattered or "collective rationality". ${ }^{120}$ The polycentric decision-making is supposed to harness this collective rationality. What is most likely to be acceptable to the group becomes, on this model, the most apt and hence, normatively recommended course to follow. On the polycentric model, it is the anticipation of what is likely to pass muster with the group which constitutes the normatively correct response to the case (these are the normative constraints on this model). And the invocation of a past case on this model serves as a rhetorical counter meant to persuade the interlocutor.

On the motivational model of normativity then, there are no normative constraints on extending the cases, which arise from the cases themselves. There are nevertheless genuine normative constraints on the decision maker. The decision maker is kept in check by tacit knowledge or sensibility of what is likely to pass muster and by perceived limits of what the legal community is likely to find persuasive. Our "ways of going on" are sufficient to hold normativity firmly in orbit without the aid of any objectively given normative constraints in past cases. ${ }^{121}$ In fact, given the standard picture of psychology going back to Hume - on which it is not "truths" that motivate, at any rate, but rather our attitudes and dispositions ${ }^{122}$ - nothing could be more stable and conducive to a normative account than a lifetime of internalisation which goes into anticipating what is likely to pass muster with the group.

One would only be setting up an Aunt Sally in supposing that, if something akin to the motivational model were to hold, we would all be plunged into a Jerome Frank-ish nihilistic legal universe; one where "anything goes", hunching reigns supreme and breakfasts dictate legal outcomes. Nothing of that sort need happen at all. Far from it, as Thomas Kuhn's work shows us, even in scientific research - ostensibly the gold standard for objectivity and truth - the truth-based model of normativity does not quite hold. ${ }^{123}$ Even in scientific research, normative constraints are generated by a process of internalisation through membership of a peer group and held in place by a sense of anticipation of what will pass muster among that group. In fact, Friedrich Nietzsche attributed the persistence of morals entirely to internalisation. ${ }^{124}$

Since the standard picture of analogical reasoning and the truth-based model of normativity underlying it have been enormously influential, the legal theorist's intuitive response here might be to suppose that underlying

120 The term is Gerald Postema's: G.J. Postema, Bentham and the Common Law Tradition (Oxford 1982), 39.

121 In any case, the Humean philosopher believes that motivation is unaffected by moral "truths": see Smith, The Moral Problem, 7-9.

122 Hume, Treatise of Human Nature, 413.

123 Kuhn, The Structure of Scientific Revolutions, passim.

124 F. Nietzsche, On the Genealogy of Morals, translated by W. Kauffman and R.J. Hollingdale (New York 1989), 84. 
the motivational model must be the truth-based model of normativity after all, so that, properly understood, the motivational model is no genuine model of normativity at all. ${ }^{125}$ There are two strands to this response which we would do well to parse out.

One strand supposes that underlying the motivational model is some normatively correct - where "correct" is understood by the lights of the truthbased model - way of reasoning analogically from past cases which is what is being tracked by this tacit knowledge with the result that the motivational model ends up elliptically referring back to the truth-based model of normativity. It is, however, of some significance to recognise that seen from a metaethically aseptic or neutral viewpoint this would have us skewing the problematic of normativity in a manner that privileges one conception of normativity (namely the truth-based model) and in limine rules out its rival conception (namely the motivational model). ${ }^{126}$ Part of the trouble comes from the very term "normativity". The term "norma" from which "normativity" derives comes from the Latin term for builder's square. From a metaethically aseptic viewpoint, an account of "normativity" must explain how an activity guides and places demands on its participants. It is an unfortunate etymological concatenation that the term "norm" tends now to be used interchangeably with "rule" or "standards" - which is something that has only served to skew the problematic of normativity. For in detecting "normativity" one is then primed to look for "norms" or "rules" underlying any practice. Doing this, however, would be unwittingly to load the dice in favour of the truth-based model of normativity. From a metaethically aseptic viewpoint, it must be acknowledged that there could be more than one plausible second-order account of the "normative" demands an activity places on its participants. One is the truth-based model and the other is the motivational model. On the motivational model, it is the anticipation by the group of what is likely to pass muster which constitutes the normatively appropriate response to the case. Hence according to the adherent of the motivational model of normativity, it would not be proper to dismiss her account of anticipation as a merely "non-normative" or "predictive". ${ }^{127}$ To illustrate the difference in the operation of the two models of normativity, it would be helpful to consider the case of natural language, which is a normative practice. The truth-based and motivational models of normativity seek to provide rival, second-order accounts of this normative practice. The truth-based model of normativity offers what is

125 I am grateful to an anonymous referee for pressing me to address these issues.

126 S. Swaminathan, "Projectivism and the Metaethical Foundations of Normativity of Law" 7 (2016) Jurisprudence 231

127 John Finnis uses a version of this objection against John Rawls's notion of "public reason". Rawls defines "public reason" as what "reasonable people may be expected to accept", which Finnis dismisses as "predictive" as opposed to "normative": J. Finnis, "On Public Reason", Oxford Legal Studies Research Paper 1/2007, available at https://papers.ssrn.com/sol3/papers.cfm?abstract_id=955815 (last accessed 13 March 2021). 
undeniably the most commonsensical account of the practice. On the truthbased model there are "rules" or "standards" of language which impinge on users of language - to borrow Simon Blackburn's expression ${ }^{128}$ - who in turn respond to the "rules" or "standards". Uses of language are truth-apt in relation to these rules or standards. The motivational model of normativity offers a rival, alternative account of this practice. On this model, the community's anticipation of what linguistic response will pass muster with language users constitutes the normatively appropriate response. It would be to misunderstand the distinct method of operation of this model if anticipation of what is likely to pass muster with the group is thought of as elliptically referring back to the correct rules or standards. On this model, uses of language are not truth-apt in relation to some rules or standards - not even in "easy" cases where controversy does not ordinarily break out, such as elementary spelling. According to the motivational model, in easy cases no less than in complex and potentially controversial cases (e.g. minting neologisms such as Simpson's "inruption"), normativity is a function of anticipating what is likely to pass muster with the group. The only difference between the easy and complex cases is here the stability of the shared responses. In easy cases, the shared responses are very stable and it is relatively easier to anticipate, even by novices; hence viewed $a b$ extra they tend to have a standard-like feel to them. Anticipation in more complex cases requires a stronger grasp, even mastery, of the practice and tends to have more of a skill-like feel to it. On this point, there are striking parallels with Wittgenstein's rule-following arguments in which he had argued that grasping a "rule" should be seen, not as extending something inherent in the rule itself, "as if they had rails laid to infinity", but rather, as anticipating the shared responses of the community of rule-followers. ${ }^{129}$

The second strand of the legal theorist's intuitive response might be to suppose that "motivational" normativity could never be genuine normativity since motivation cannot really come apart from "rationality" and that one cannot motivate interlocutors into doing "irrational" things - not systematically at any rate. Hence, what must truly motivate interlocutors, the objection goes, is genuinely "rational" requirements which should remain unaccounted on the motivational model. Notice how this response too supposes the truth-based model of normativity and tacks it onto "rationality". The supposition here is that there are such things as "standards" of rationality which impinge on agents, which they ought to be responsive to. But this again would be to load the dice in favour the truth-based model of normativity. According to the "standard picture of psychology" discussed

128 S. Blackburn, Spreading the Word (Oxford 1984), 181.

129 L. Wittgenstein, Philosophical Investigations, translated by G.E.M. Anscombe (Oxford 1991), 53-88 (§§ 138-242). The most prominent advocate of this reading of Wittgenstein is Saul Kripke, whose reading is evidently a Humean one: S. Kripke, Wittgenstein on Rules and Private Language (Oxford 1982), 88-95. 
earlier, widely endorsed by philosophers across the metaethical spectrum, states of mind are divided into cognitive states such as beliefs (motivationally inert) and conative states such as attitudes (motivationally active). What are classified here as "rational" requirements or standards would fall on the "cognitive" side of the table which means that they would be motivationally inert. Any motivation would necessarily involve having to affect the interlocutor's conative states (e.g. attitudes) - which is the central point of rhetoric as Campbell put it. Hence, the supporters of the motivational model will counterclaim that it is their model alone which explains motivation, not the truth-based model. If this response leaves the legal theorist with the residual unease that the motivational model lacks "normative standards" external to the communal or practice-generated consensus - which is the fulcrum of the motivational model - it may be pointed out that this is the fundamental point on which the motivational model differs from truthbased model. On the motivational model, there is no standard or requirement beyond the practice which normatively regulates moves within it. The "ways of going on" are the source of normativity. Therefore, this point again only serves to illustrate the difference in the working of the two models rather than show that the motivational model is wrong.

All said and done, this paper does not seek to argue that the truth-based model of normativity is wrong or that the motivational model is right. To be sure, the onus of establishing that metaethically would be a heavy one indeed and cannot even begin to be discharged within the interstices of a paper on analogical reasoning in law. Rather, this paper simply rests on a plea to recognise that, from a metaethically aseptic viewpoint, there are two plausible models of understanding normativity; one is the truth-based one while the other is the motivational model. And it rests on a plea, that the motivational model of normativity should not in limine be ruled out, as it tends to be. As such, it makes the case for bringing into reckoning a philosophical account which tends to be neglected by legal theorists.

The truth-based model of normativity tends to have such a strong hold on legal theorists that it is often easy to overlook the availability of an alternative. To this must be added the negative image of rhetoric which gives scholars further cause to give a wide berth to the motivational model of normativity. As a consequence, a philosophically robust alternative to the truth-based model of normativity in common law reasoning has not been forthcoming. This is where the polycentric account based on a motivational model of normativity holds such promise. It provides a theoretical alternative to the truth-based model and has the potential to co-opt theoretical positions about the common law based on tacit knowledge (e.g. those of Llewellyn and Dagan) and persuasion and rhetoric (e.g. those of Viehweg and Stone) which are opposed to the truth-based account, within the fold of a unified theoretical rubric spanning both epistemology and justification. The value of this unified theoretical rubric that combines tacit 
knowledge (anticipatory prong) and rhetoric and persuasion (justificatory prong) cannot be overstated. Even in the accounts of those like Fish who endorse both tacit knowledge and rhetoric, the two operate in separate silos rather than coming together in an integrated whole as they do in the polycentric account. Neither (1) the anticipatory prong pertaining to tacit knowledge, nor (2) the justificatory prong pertaining to persuasion, taken in isolation, is capable of yielding normativity which is a plausible alternative to the truth-based model. Taken in isolation, an account which relies on anticipation alone or persuasion alone runs the risk of coming across as an unstable mishmash of elements mimicking the truth-based model of normativity. Thus, the act of anticipation could be charged with elliptically referring back to true standards which agents seek to respond to - much like the intuitive response of the legal theorist as we have seen previously. It would need more to anchor normativity in an alternative account. Taken alone, the justificatory prong pertaining to persuasion alone runs into a problem of a different kind. It would not be immediately obvious what are the normative constraints on this account. Without the assurance of normative constraints, any persuasion-based account carries the risk of morphing into an "anything goes" or a pejorative variety of rhetoric. An illustration of this point is the criticism directed against a particular strand of Humean accounts of ethics namely, non-cognitivist accounts such as those of A.J. Ayer, Charles Stevenson, Simon Blackburn and Allan Gibbard. And among the modern non-cognitivists' attempts to parry these criticisms is one involving falling back on something akin to normative constraints generated by anticipation of what will pass muster with the community, of the sort discussed here. ${ }^{130}$ It could, in fact, be argued that Hume's account of "artificial justice" combines the two prongs although they are not brought together as clearly as they are in Polanyi's account. ${ }^{131}$ The key contribution of Polanyi's account of polycentricity lies in unifying the two prongs of anticipation and rhetoric under the rubric of a unified account where the two dovetail into each other to yield genuine normativity without either prong rendering the other redundant. The basic building block of normativity in this model is what will be accepted by the group. The agent seeks to have her piece of reasoning pass muster with the group. The anticipatory prong is what lets the agent know what will pass muster with the community. And the justificatory prong is the action that actualises it. Both prongs look in the same direction, as it were - which is to say, towards what will pass muster with the group. To return to the pricing example considered earlier, it involves both anticipating how a market will react at different price points and actually offering a product for sale in the market with certain specifications at a certain price point. Neither prong is otiose or

\footnotetext{
130 S. Blackburn, Ruling Passions (Oxford 1998).

131 Hume, Treatise of Human Nature, 477-573.
} 
redundant. In the legal case, the anticipatory prong which gives a reasoner the sense of what is likely to be acceptable to the group combines with the justificatory prong involving articulation of reasons to form what is called "legal reasoning".

\section{ANALOgy ReVERSED}

The alternative account of analogical reasoning sketched here reverses the orientation or direction of fit between what we are schooled to treat as the "source" and "target" in analogical reasoning. On this account, the direction of fit of analogical reasoning is found to be from what is ordinarily understood as "target" (present case) to the so-called "source" (past case). A common law judge acting polycentrically is lead, through tacit knowing developed over years, to what is the apt outcome in the present case. On the motivational model of normativity presupposed by the polycentric method, the anticipation of what will pass muster with the legal community constitutes the normatively correct response to the case. The function of the invocation of the past case is persuasion - the past cases (the putative analogues, here reversed to "targets") are picked and framed in certain ways for their value as rhetorical counters to justify the decision independently reached in the case at hand. They purport to have motivational traction in the practical reasoning of the interlocutor by showing how the case at hand is suitably similar or alike to another past decision. Analogical reasoning is thus seen as fundamentally rhetorical - albeit with robust normative constraints in place.

Two rather important features connected with "analogical reasoning" which have been co-opted by the standard picture - and occasionally even pitched as justifications for it - have turned out to be fiendishly difficult to account for: (1) that analogical reasoning is justified by the principle of "treating like cases alike"132 and (2) that analogical reasoning makes courts stick to incremental changes. ${ }^{133}$ Despite the deceptive air of simplicity that the principle of "treating like cases ... alike" has about it, it has been embarrassingly hard to sustain. As Raz argues, something wrong done in the past hardly justifies the repetition of the wrong on this occasion. ${ }^{134}$ If something gives reason to be followed, it should do so because it commends itself as the thing to be done - which indicates that what does the justificatory job here is substantive reason underlying the earlier decision, not the formal ground of repeating the past, regardless of its merit. Even the justification that analogical reasoning is to be welcomed since it leads to incremental change in the common law turns out to be hard to sustain since there is nothing in the standard picture of ana-

132 Burton, Introduction to Law and Legal Reasoning, 26.

133 Sunstein, Legal Reasoning and Political Conflict, 62-100; King, Judging Social Rights, 296.

134 J. Raz, "Professor Dworkin's Theory of Rights" (1978) 26 Political Studies 123, 135. 
logical reasoning which constrains the judge to making incremental changes. As Posner argues, it is not clear why reasoning by analogy should necessarily lead to incremental change. ${ }^{135}$ There is no reason why courts adhering to what is understood as analogical reasoning ought to limit it to changes which are incremental in nature. After all, if the courts are extending, there is no constraint on the extent to which they might extend. To revisit an example from earlier in the article, there is nothing in the standard picture which prevents Taylor $v$ Caldwell from being potentially extended to "frustration of commercial object" - which would not be an "incremental" extension. By the lights of the standard picture then, any incrementalism that analogical reasoning might achieve then seems purely contingent. However, both these principles are intuitively felt too close to analogical reasoning to be cast by the wayside in this manner - and in so far as an alternative account does a better job of making sense of them, it should count in favour of such an account. Indeed, the alternative account of analogical reasoning sketched here salvages both these principles and conserves their close link to the process.

The idea of treating "like cases alike" is transformed when viewed in rhetorical terms, as a lever for persuasion. Seen along the lines of the polycentric model, the process involves, not a "discovery" of likeness to a past case, but rather "justification" of the present decision by appeal to likeness of a past case to the present one. It should be readily apparent how Perelman made this formal principle of treating "like case ... alike" the pillar of his rhetorical account and even went so far as to describe it as the principle of justice. ${ }^{136}$ Here, the direction of fit of judgments of likeness is the reverse of what it is on standard accounts of analogical reasoning. This also explains the otherwise poorly understood connection between analogical reasoning and incrementalism in the common law. The closer new decisions are kept to older ones which are being invoked as rhetorical counters, the more acceptable or persuasive they are likely to be. ${ }^{137}$ This is so because of the two Humean principles of contiguity and similarity. Seen thus, common law incrementalism is also closely connected to rhetoric. ${ }^{138}$

The reversal of the direction of analogical reasoning proposed here underlines the idea - counterintuitive at first blush - that the legal past is not static. Jorge Luis Borges once noted that, while ordinarily one seeks to establish which literary precursor influenced the present writer, the not so obvious fact is that "every writer creates his own precursors". ${ }^{139}$

135 Posner, Problems, 92.

136 H. Berman, "Introduction" in C. Perelman, Justice, Law, and Argument: Essays on Moral and Legal Reasoning (Dordrecht 1980), x.

137 See Postema, Bentham and the Common Law Tradition, 79.

138 Perelman and Olbrechts-Tyteca, The New Rhetoric, 106-07.

139 J.L. Borges, "Kafka and His Precursors" in E. Weinberger (ed.), Selected Non-Fictions (New York 1999), 363, 365. 
Similarly, common law decisions create their past analogues - which the polycentric account of analogical reasoning helps us to understand. And, in doing so, common law decisions not only modify the future (which is often obvious) but also modify our perception of the legal past (which is often not obvious). 